Flory, A. - A recepção de B. Brecht

\title{
Apontamentos sobre a recepção de Bertolt Brecht no Brasil via Anatol Rosenfeld
}

[Notes on Berthold Brecht's reception in Brazil, by Anatol Rosenfeld]

Alexandre Villibor Flory ${ }^{1}$

\begin{abstract}
One of the most important chapters in the reception of German theater in Brazil began in 1958 with the presentation of Berthold Brecht's play The Good Woman of Setsuan. The subsequent performance of many of his works brought up new dramaturgic and theoretical questions in a context that was open to aesthetic experimentation and marked by a dialectic between the theater and the turbulent social context of the period. Groups such as Arena, Oficina, and CPC discussed, updated and articulated Brecht's work through their experimentation. Since this reception in Brazil, both in the late 1950s and today, is based on several different theoretical and critical references, it would seem well to go back to Anatol Rosenfeld's critique of Brecht. From his broad knowledge of aesthetic theater, epic theater theory, Brazilian theater and Brecht's work, Rosenfeld holds an important place in the debates on Brecht's works and Brecht's influence on Brazilian theater. In this article we take up several phases in Rosenfeld's work, which is theoretical as well as historical and critical. His contributions are considered among the most lucid and updated studies on Brecht and the Brazilian theater.
\end{abstract}

Keywords: Berthold Brecht; Anatol Rosenfeld; Brazilian theater; theater and society

Resumo: Um dos capítulos mais importantes da recepção do teatro alemão no Brasil se iniciou em 1958, com a montagem de A alma boa de Setsuan. A encenação de muitas entre suas obras a partir de então colocou novas questões dramatúrgicas e teóricas num cenário aberto à experimentação estética e marcado pela dialética entre o teatro e o turbulento contexto social brasileiro da época. Grupos como o Arena, o Oficina e o CPC discutiram, atualizaram e articularam a obra de Brecht com suas próprias pesquisas. Como essa recepção, ontem como hoje no Brasil, é feita a partir dos mais diferentes referenciais teóricos e críticos, faz-se necessária a revisitação da crítica esclarecedora de Anatol Rosenfeld sobre Brecht. Profundo conhecedor de estética teatral, da teoria do teatro épico, da obra de Brecht e do teatro brasileiro, Rosenfeld tem papel decisivo em vários debates em torno de sua obra e de sua influência no teatro brasileiro. Nesse artigo, a partir de questões que surgem da recepção contemporânea de Brecht, pretendemos acompanhar algumas etapas desse percurso na obra de Rosenfeld, que é tanto teórico como histórico e crítico e se constitui como um dos mais lúcidos e atuais estudos sobre Brecht e o teatro brasileiro.

Palavras-chave: Bertolt Brecht; Anatol Rosenfeld; teatro brasileiro; teatro e sociedade.

\footnotetext{
${ }^{1}$ Doutor e professor adjunto da UEM - Universidade Estadual de Maringá. Email: alexandre_flory@yahoo.com.br
} 
Flory, A. - A recepção de B. Brecht

\section{Introdução}

O teatro de Bertolt Brecht está bastante vivo no Brasil hoje. Uma rápida olhada nas últimas temporadas teatrais mostra um espectro que vai da global Denise Fraga montando A alma boa de Setsuan ao envolvimento profundo de grupos como a Cia do Latão e o Teatro de Narradores com sua obra teórica e dramatúrgica. Além disso, muitas encenações, como a de Acordes, dirigida por Zé Celso no Teatro Oficina, bem como os mineiros do Galpão com Homem é homem e dos gaúchos do Ói Nóis Aqui Traveis, com A exceção e a regra, entre muitas outras, marcam os palcos brasileiros dos últimos anos do século XX ao início do XXI. Sem esquecer, é claro, do XIV Simpósio da Sociedade Internacional Brecht, que ocorreu em Porto Alegre, em maio de 2013, ponto de partida das nossas considerações.

Devemos começar anotando que o teatro de Bertolt Brecht sobreviveu, no mínimo, a duas mortes anunciadas, uma de fundo estético e outra social. A primeira está relacionada à sua suposta obsolescência diante do assim chamado teatro do absurdo e às vertentes pós-dramáticas, tendências que o concebiam preso ao texto e à lógica racionalista, em uma leitura histórica que não vê diferenças entre o drama burguês do século XIX e as perspectivas épicas a partir da crise desse drama, por exemplo ${ }^{2}$. A segunda dessas mortes anunciadas adviria do término do bloco soviético, que teria feito de seu teatro peça de museu, pelo fim do horizonte político a que seu teatro estaria subordinado.

Seu teatro talvez não consiga, no entanto, superar a sua terceira morte, a que decorre do desmonte gradual e ininterrupto de seus dispositivos dialéticos e materialistas, diluindo sua teoria e prática em técnicas isoláveis e adaptáveis a quaisquer obras (como, por exemplo, o conceito de estranhamento ${ }^{3}$ ): torna-se, assim, parte de uma espécie de fundo comum brechtiano já ‘absorvido' e ‘incorporado' pela cultura teatral. Do mesmo naipe aniquilador é etiquetá-lo como clássico atemporal, que pede

\footnotetext{
${ }^{2}$ Essa leitura se encontra em uma obra como $O$ teatro pós-dramático, de Hans-Thies Lehmann, por exemplo. Cf., a esse respeito, seu conceito ampliado de drama. "Coro, narrador, intermédio, teatro no teatro, prólogo e epílogo, apartes e milhares de fendas sutis no cosmos dramático, o repertório brechtiano da representação épica enfim, podiam ser acrescentados e integrados "ao" drama sem perturbar a vivência específica do teatro dramático." (2007: 26)

${ }^{3}$ Schwarz mostra que o estranhamento já chegou até mesmo à publicidade, completamente alienado de seus elementos críticos, questionando sua eficácia atual (SCHWARZ 1999: 130). Contudo CARVALHO (2009: 49), em resposta a Schwarz, mostra que, sem a crítica social que lhe confere sentido, não se pode falar em estranhamento. Não se trata apenas de uma técnica, mas de um efeito sobre o público.
} 
Flory, A. - A recepção de B. Brecht

reverência, lado a lado com outros monstros sagrados da literatura e dos palcos, com um rótulo que vende bem. Seu trabalho não está nem mesmo protegido de sua acomodação a tendências pós-modernas que apostam no vale-tudo semântico e no recuo à subjetividade criadora como instância preferencial do debate artístico e social.

Esse processo de esvaziamento e desarme estético-ideológico nos é apresentado, contraditoriamente, pelos seus defensores, como a eternização de sua obra, como uma 'superação dialética', quando na verdade a domestica por se afastar de alguns de seus pressupostos fundamentais. Não podemos nos esquecer que, como dito pelo próprio Brecht, o teatro épico "pressupõe, além de um certo nível técnico, um poderoso movimento social, interessado na livre discussão de seus problemas vitais e capaz de defender esse interesse contra todas as tendências adversas." (BRECHT apud COSTA 1990: 103). De modo mais sucinto porém incisivo, nas palavras de Benjamin: "Quem precisaria dizer o essencial sobre Brecht em três palavras, faria bem em limitar-se à frase: Seu assunto é a pobreza." (1986: 122) Essa perspectiva, que nos parece definitivamente atual e necessária, também encontra espaço no cenário atual do teatro brasileiro, atualizando uma recepção que remonta aos anos 1960.

\section{XIV Simpósio Internacional Brecht}

Essas considerações foram elaboradas num pano de fundo muito específico, a saber, o já mencionado XIV Simpósio da Sociedade Internacional Brecht, que se realizou em Porto Alegre no final de maio de 2013. Se é verdade que nele todas as possibilidades antagônicas acima arroladas marcaram presença, deve-se anotar que a perspectiva materialista dialética era não só minoritária como marginal, o que pede discussão. Vale a pena, portanto, comentar mais amiúde o texto de chamada desse Simpósio para justificar o recorte para esse artigo. Sob o título $O$ espectador criativo: colisão $e$ diálogo, o texto de chamada começa assim:

O sentido político do teatro, na perspectiva de Bertolt Brecht, deve ser atualmente concebido em termos do papel do espectador e o apelo de Brecht a uma nova "arte do espectador" pode unicamente ser hoje abordado no contexto da cultura midiática, no qual as práticas da recepção têm sofrido mudanças drásticas. O público que hoje consome música, televisão ou filmes está distraído; as pessoas usam smartphones e internet e estão acostumadas a uma comunicação superficial, mas imediata e interativa. Quais são então as oportunidades que o teatro politicamente orientado possui, nesse 
Flory, A. - A recepção de B. Brecht

contexto de mudanças, para incentivar o público em sua própria criatividade? [...] O teatro se torna político por interrogar sua própria prática, tornando-a seu tema e problema. Ele se dirige a espectadores criativos que não desejam respostas prontas, mas buscam no teatro a matéria com a qual possam eles mesmos criar, de maneira precisa, suas próprias perguntas e respostas. (Disponível em http://brechtportoalegre.com/ Acesso a 19 de junho de 2013.)

O mote do Simpósio, “o espectador criativo”, fazia esperar por uma discussão sobre os pressupostos materiais da alienação e do isolamento do sujeito no contexto contemporâneo, em suas variações da época de Brecht para cá e, ainda, de sua atualização para o Brasil. Antes de pensá-lo criativo, seria indispensável estudar o que se entende por sujeito. A nosso ver, isso se impõe como exigência para qualquer crítica (anti)capitalista que se pretenda fazer nesse nível. Sem desconhecer, com Schwarz (1999), que os capitalistas mudaram, os proletários idem (agora repaginados como colaboradores) e que as estruturas de encobrimento já não precisam dourar a pílula dos interesses materiais - econômicos - imediatos, a dinâmica do capitalismo sob o neoliberalismo produz desigualdades sociais cada vez maiores, que são encobertas e naturalizadas por processos ideológicos específicos de cada lugar e época. Entre outras coisas, a suposta ausência de alternativas ao capitalismo neoliberal resulta num mascaramento dos mais perniciosos: todos os problemas e dissonâncias entram na conta das contingências, ao invés de serem tomadas como estruturas íntimas do sistema.

O texto citado, no entanto, passa longe dessa dimensão crítica. Esse mundo virtual aceito como dado não é investigado em sua dimensão mercadológica, como discurso do capital, que exija uma visada crítica e dialética para se contrapor ao enunciado da forma - que só aceita ver a virtualidade contemporânea de modo neutro e positivo. Apela-se para sua utilização pois, afinal de contas, "o apelo de Brecht a uma nova "arte do espectador" pode unicamente ser hoje abordado no contexto da cultura midiática." (id.). A percepção distraída por pessoas "acostumadas à uma comunicação superficial, mas imediata e interativa" não é colocada sob a rubrica do aprofundamento da alienação e do esvaziamento do sujeito num contexto virtual, contra quaisquer demandas coletivas de longo alcance e com debate continuado.

Como num ritual, o teatro seria um espaço de uma coletividade transitória e efêmera, que só naquelas circunstâncias conseguiria se armar como um lugar de 'reflexão compartilhada'. Sendo assim, o nível político, social e estético decisivos migram para a subjetividade, aceitando passivamente a atomização social radical e o 
Flory, A. - A recepção de B. Brecht

culto da autoajuda. Esse é o lugar da 'criatividade' desse público, espectadores que "buscam no teatro a matéria com a qual possam eles mesmos criar, de maneira precisa, suas próprias perguntas e respostas". Sendo assim, as perguntas e as respostas não são coletivas e sociais, impostas pelas crises políticas, econômicas, ambientais e culturais com as quais hoje convivemos, mas criadas e resolvidas pelo indivíduo fechado sobre si mesmo. Em nenhum momento, por sinal, essa dimensão material básica é levantada como parte, mínima que seja, das questões estéticas, que pairam livres no céu da autorreferencialidade. Parece que, por mero decurso de prazo, estão superadas questões como 'o ser social determina o pensamento'. Como estamos distantes das palavras de Pasta, cuja eloquência soa já no título de seu artigo - 'Brecht: a beleza materialista'.

Recorde-se apenas, por um momento, que cada signo de sua obra madura [de Brecht] se fez como um gesto tensionado, de um lado, pelo nazismo e, de outro, pelo desejo da sociedade revolucionada ou da humanidade liberada. Entre esses dois extremos, e explicando-os (tal como faz a tradição marxista, da qual ele é inseparável), Brecht via um combate central: a luta de classes - e essa foi a pauta principal que deu a seu próprio trabalho. (PASTA 1998: s/p)

Retornemos ao texto do Simpósio. "O teatro se torna político por interrogar sua própria prática, tornando-a seu tema e problema." Entenda-se: o metateatro é político por sua própria natureza artística? Ele é político, como espaço de 'reflexão compartilhada', mas sobre que materiais? Sobre o próprio teatro? Claro, é bem-vinda a ideia de que as respostas não venham do palco, mas não se põe a questão de como ativar politicamente as pessoas num ambiente hostil, cada vez mais fragmentado, com a dimensão hipertextual das relações em fluxo contínuo e marcadas pela antisseriação dificultando, quando não impedindo, um pensamento dialético racional? Em outras palavras, em que medida o caráter coordenativo, analógico e multiperspectívico das relações hipertextuais não bloqueia/dispersa a argumentação subordinativa necessária à dialética, pautada por contradições que façam sentido, quando tomadas historicamente? O texto ora discutido vê apenas positivamente essas questões, de modo unilateral. Festejam-se e elogiam-se as novas possibilidades abertas por essas mudanças, encampando o discurso prótecnologia e da 'liberdade' do sujeito trazida pelas novas mídias. A atitude é pouco dialética, se o é em alguma medida.

Não só deixa de historicizar como deixa de problematizar, fazendo-o apenas e tão somente quando restritos à dimensão subjetiva - que se torna, portanto, a única 
Flory, A. - A recepção de B. Brecht

dimensão política e estética relevante. Assim se entende que esse teatro "se dirige a espectadores criativos que não desejam respostas prontas, mas buscam no teatro a matéria com a qual possam eles mesmos criar, de maneira precisa, suas próprias perguntas e respostas." (negritos meus). Retomando: os espectadores criam suas próprias perguntas e respostas? Não há questões coletivas relevantes? Ora, semanas depois os brasileiros foram às ruas em manifestações que tomaram o país e ainda estão por serem compreendidas, contrariando esse processo subjetivo realizado à revelia quero crer - do pensamento teórico e prático de Brecht.

Em suma, a crítica materialista é abandonada em função de um idealismo autorreferente. A crítica da sociedade capitalista e da distância entre os mais ricos e os mais pobres, ainda mais em tempos de neoliberalismo exacerbado, não teve o espaço que merecia, ficando restrita a uma apresentação teatral da Cia do Latão e a poucas comunicações. A suposta liberdade do sujeito individual e autônomo é asseverada, não vista contraditoriamente como formada coletivamente, assim como a consciência. Desse modo, a fragmentação do sujeito e seus correlatos ganha estatuto ontológico, não histórico. Essas posições seriam criticáveis em qualquer quadro estético, mas tornam-se especialmente problemáticas quando se trata de uma discussão sobre Bertolt Brecht.

\section{$2 \bigcirc$ grupo Pocha Nostra e a Cia do Latão: contradições inconciliáveis}

Como grupo apresentado oficialmente entre as atividades do Simpósio em questão estava o grupo americano Pocha Nostra, bem afinado a uma das linhas de chamada do mesmo, que pedia: "Teatro voltado ao performativo, que envolve o público intelectual e fisicamente; [...] Teatro com atores não profissionais, no qual se subverte a percepção puramente estética da pessoa no palco.” Como se lê em seu manifesto 2012,

La Pocha Nostra is a virtual maquiladora, a conceptual assembly plant that produces brand-new metaphors, symbols, images, and words to articulate the complexities of our times. [...] The Spanglish neologism Pocha Nostra translates as either "our impurities" or "the cartel of cultural bastards." We love this poetic ambiguity. It reveals an attitude towards art and society: Cross-racial, cross-national, poly-gendered, post-ultra-retroexperimental or a remix of the same, ¿y qué? ¿Cuál es el pedo?

La Pocha Nostra is an intercultural poltergeist. We are a migrant dream that suddenly becomes a nightmare; a pagan religion located in the body, a bunch of 
Flory, A. - A recepção de B. Brecht

malfunctioning cyborgs, a deterritorialized desire, and deeply committed friends. (POCHA NOSTRA 2012: s/p)

Os termos falam por si sós: "uma fábrica de metáforas novas em folha, símbolos, imagens e palavras para articular as complexidades de nossos tempos"; mas em nenhum lugar essas complexidades são apresentadas, ou mais: elas se perdem em meio às demandas por reconhecimento que buscam romper toda e qualquer fronteira. Mais adiante, uma atitude frente à arte e à sociedade que se propõe "cross-racial, crossnacional, poligênero, pós-ultra-retro-experimental (sic) [...] um sonho que se torna um pesadelo; uma religião pagã localizada no corpo, ciborgues que funcionam mal, um desejo desterritorializado" e por aí afora. Corroborando as questões levantadas a partir da chamada do Simpósio, vemos o fechamento em torno da encenação quase ritualizada (religião pagã, etc), que se limita ao mundo dos sonhos/pesadelos que se concentram numa subjetividade que é antes corpo que consciência, antes desejos desterritorializados que interesses localizados e concretos, discutidos social e historicamente. A peça é construída sobre sonhos fetichistas, esquetes que chocam a sensibilidade burguesa, incitação à participação do público que pode e deve, inclusive, fotografar as performances realizadas por artistas locais dirigidos pelo grupo. Aos problemas já vistos se somam o tema e a forma da irracionalidade.

Difícil não remeter ao delicioso artigo de Anatol Rosenfeld intitulado Irracionalismo epidêmico, em que comenta o grupo americano Living Theatre, que esteve no Brasil no início dos anos 1970 a convite de Zé Celso. Após uma citação longa de um trecho de uma entrevista de um jovem artista de teatro ligado ao grupo, que cultiva o kaos e que Rosenfeld qualifica como 'mingau verbal', ele dirá:

Não há nada mais indiferente que o "diferente". Incrível como esses individualistas antilineares se massificam na linearidade tipográfica e como sua suposta espontaneidade vira clichê no "jargão do espontaneísmo", hoje artigo de supermercado. Com que rapidez a investida anticoisificação se coisifica, pô. (ROSENFELD 1993: 208)

Mais adiante, passa a falar especificamente dessa fase do Oficina e sua proximidade com a estética do grupo americano: ambas buscam

"envolvimento" do público, convite mais ou menos agressivo para que "participe" no "ritual" e se torne "coator", por mais que se sinta constrangido, tudo dentro de um 
Flory, A. - A recepção de B. Brecht

contexto anarcomístico com tendência à salvação do mundo pelo antipalco e pelas contraconcepções de um teatro desapropriado de seu "r" (para passar às vias de "ato"). (ROSENFELD 1993: 210).

Por outro lado, em contraposição a essa perspectiva, a Cia do Latão também se apresentou no Simpósio, com a peça $O$ patrão cordial, fruto de uma pesquisa de cunho materialista e que leva em conta não apenas a dinâmica atual do capitalismo financeiro como, também, questões fundamentais da complexa formação social e política brasileira. O conceito do "homem cordial", que Sérgio Buarque de Hollanda cunha no fundamental Raízes do Brasil, expressa-se em termos de uma 'cordialidade puntilliana' (expressão de Anatol Rosenfeld) de grande força estética e política. Numa linha de pesquisa e atuação estável sobre o teatro dialético no Brasil, o grupo se consolidou como um dos mais importantes do país ao longo dos últimos 15 anos, tornando-se uma referência obrigatória ao estudo da arte contemporânea no Brasil. Suas bases remontam às experiências formais e ao trabalho de grupos como o teatro de Arena e ao CPC, bem como à tradição épica que passa, necessariamente, por Brecht.

De fato, esse quadro esquisito da recepção de Brecht no Brasil, com variedades incompatíveis dialeticamente ${ }^{4}$, pede uma reafirmação e revisitação crítica a partir de sua chegada. Não há melhor nome, no caso, do que a retomada do pensamento teatral de Anatol Rosenfeld, para colocar as ideias em ordem, dialética e materialmente. O mesmo Rosenfeld que escreveu textos fundamentais sobre o irracionalismo teatral foi interlocutor privilegiado do teatro de Arena, especialmente após o golpe de 1964, com destaque para os textos sobre o Sistema Coringa.

\footnotetext{
${ }^{4}$ Com certeza, há muitas outras possibilidades de atualização da obra de Brecht no cenário teatral brasileiro nos dias de hoje. Para citar poucos, gostaria de mencionar sua influência sobre os processos de trabalho do Coletivo de Teatro Alfenim, da Paraíba, grupo que surge em 2007; o mesmo vale para o Teatro de Narradores, de São Paulo, não apenas quando encenam, na rua, A resistível ascensão de Arturo Ui, em 2013. Cito também a Cia do Feijão, por exemplo em sua mais recente montagem, Armadilhas brasileiras, de 2013, com cenas do filme Kuhle Wampe absolutamente à vontade na montagem; ainda vale menção a encenação de Um homem é um homem, pelo grupo Galpão, de Minas Gerais, em 2006. Todas essas peças e grupos, entre muitos outros que não cabem na limitação de um artigo, trabalham com teatro dialético, em vertentes as mais diversas e, cada qual a seu modo, realizando uma atualização crítica da obra de Brecht e do teatro épico-dialético, o que merece atenção e pesquisa. Porém, nesse artigo, a remissão a uma incompatibilidade completa entre a proposta irracionalista de um grupo como o Pocha Nostra e o materialismo dialético da Cia do Latão, além da grande tensão pelas diferenças, se impõe por ambas marcarem presença na programação oficial do XIV Simpósio Internacional Brecht. De um lado (Pocha Nostra), traz à tona a discussão irracionalista já no final dos anos 1960 no Brasil; de outro lado (Latão), um grupo articulado com a tradição dialética do teatro de Arena, também dos anos 1960. Ora, o quadro é propício para retomar o pensamento teatral de Anatol Rosenfeld, chegando assim ao tema central do artigo, e já provando sua atualidade assustadora nos dias de hoje.
} 
Flory, A. - A recepção de B. Brecht

\section{Anatol Rosenfeld e sua leitura de Brecht (no Brasil)}

Rosenfeld soube não apenas nos apresentar as obras de Brecht - teoria e dramaturgia, sobretudo - como também fazer a crítica primeira e encaminhar a recepção no Brasil desde sua chegada aos nossos palcos, em 1958. Uma das linhas de trabalho de Rosenfeld no âmbito dos estudos teatrais brasileiros trata da recepção da tradição do teatro alemão no Brasil, especialmente de Brecht. Nascido em Berlim em 1912, estudou filosofia, teoria da literatura e história, com especialização em Letras Alemãs, entre 1930 e 1934 na Universidade de Berlim (ROSENFELD 2006). Isso o coloca no centro de um intenso debate artístico e teatral na República de Weimar e que deságua na fase nazista, a partir de 1933. GuINSBURG (1995) encontrou em seu espólio ingressos que mostram seu interesse pelo teatro ainda adolescente. Em $O$ teatro épico, lê-se que assistiu a uma encenação de Um homem é um homem, em Berlim, em 1931, também mencionada em artigo fundamental de Walter Benjamin sobre o teatro épico de Brecht (BENJAMIN 1996: 79-80). Esse percurso o credencia para o papel decisivo que desempenhou na recepção de Brecht no Brasil quando esse por aqui aportou, em 1958 (no teatro profissional), com a montagem de A alma boa de Se-tsuan, por Maria Della Costa.

O teatro brasileiro, no mesmo ano de 1958, entrava em uma nova fase com o sucesso de Eles não usam Black-Tie no teatro de Arena, de busca formal e temática. O processo se viabiliza pelo surgimento de grupos como o próprio Arena, o CPC, o MCP em Pernambuco, o Grupo Opinião no Rio de Janeiro, entre outros. Nesse momento, a recepção de Brecht se fazia oportuna não como um clássico atemporal, mas por uma necessidade objetiva brasileira, social, política e cultural.

Black-Tie foi a primeira peça a colocar operários em cena com conflitos girando em torno de uma greve - assunto épico - embora acabe se restringindo a uma moldura formal ainda dramática, materializada em conflitos domésticos. No entanto, já é resultado palpável dessa busca. Nas palavras de SzONDI (2001: 25), o enunciado do conteúdo entra em contradição com o da forma, numa dialética muito produtiva, desde que seja o ponto de partida para um debate profícuo. Brecht seria fundamental nesse processo, pois sua obra também surgira num contexto politicamente turbulento, com 
Flory, A. - A recepção de B. Brecht

possibilidades abertas de mudanças sociais significativas, como era o caso do Brasil então.

Costa (2012) mostra como foi oportuna a montagem de Maria della Costa justamente pela concomitância com o Black-tie de Guarnieri. De repente, questões sobre formas dramáticas para expressão de novos conteúdos, que tiravam o sono dos integrantes do Arena, ganhavam uma interlocução estética (e social) que se impunha de modo inexorável. Vianinha afirma que os integrantes do Arena debatiam madrugada adentro a encenação de Setsuan, muito produtiva mesmo quando não se concordava com ela. De fato, Rosenfeld mostrava já em 1956, no artigo 'Disciplina do coração', a necessidade de se pensar novas formas para expressar novos conteúdos, a partir de Brecht. Por exemplo:

O calor poético ou a melancolia elegíaca de Brecht (a busca da dissolução na natureza, depois substituída pela integração no ativismo marxista) não cederam ao novo realismo: este apenas se superpôs àquela vibração expressionista, cobriu-a, por assim dizer, com a língua metálica da épica. [...] Brasa envolvida em gelo, fenômeno universal. A desconfiança nas palavras, o pudor de empregá-las assumem tais aspectos que no palco já não é possível dizer: "eu te amo". Hoje a declaração de amor se faz às avessas. Eis as raízes profundas do $V$-effekt, isto é, o que se poderia denominar de técnica desilusionista do teatro. A desconfiança à palavra emotiva e à emoção em geral (contaminada pela sociedade capitalista, como mais tarde diria ele) leva-o a impedir a identificação do público com o mundo poético do palco. [...] Tratar-se ia, disse Brecht, "de uma técnica que aliena o familiar." (ROSENFELD 1956: s/p).

Esse excerto explicita a profundidade dos seus conhecimentos sobre a obra de Brecht no momento em que, com as excursões do Berliner Ensemble por Paris e Londres, seu nome ganhava espaço no cenário teatral internacional. Rosenfeld não apenas se refere à sua fase 'expressionista' como a matiza, o que vale para obras específicas como Baal mas que interessa, sobretudo, para se acompanhar historicamente sua produção. As influências naturalistas (realismo) e expressionistas estão ambas presentes, tensionandose formalmente no campo dos temas, das formas e da linguagem, aliás um dos campos mais importantes para o estudo da obra de Brecht - e não só pelo fato de ele ser, também, poeta, pois essa 'desconfiança nas palavras' (e tornar consciente a ideologia que elas carregam consigo) ganha um nível de elaboração ímpar em seu teatro. ${ }^{5}$ Nesse momento, tratava-se de trazer Brecht para o debate e contribuir para sua disseminação,

\footnotetext{
${ }^{5}$ Cf, a esse respeito, Roberto SCHWARZ (1999), especialmente quando discute o uso dos clássicos da poesia alemã pelo capitalista Bocarra, de Santa Joana dos matadouros.
} 
Flory, A. - A recepção de B. Brecht

além de lutar contra seu rebaixamento. Por fim, historiciza a obra de Brecht, não a tomando como um todo único, monocórdico e atemporal. Rosenfeld afirma, ainda, que Brecht não é contra as emoções, mas as vê, no cenário de então, contaminadas pela sociedade capitalista - o que servirá de base para sua concepção de diversão, como se lê no 'Pequeno Órganon para o teatro'. Ele quer uma diversão crítica, afastando-a do consumo boçal. O título do artigo não deixa dúvida: a disciplina do coração é tanto uma atividade crítica (disciplinar o coração, corroído que está pela sociedade capitalista) quanto um conjunto de conhecimentos e avaliações críticas articulados e organizados (uma disciplina): nos dois casos, o coração não é expulso de suas considerações, antes valorizado nelas.

A integridade intelectual de Rosenfeld fica patente quando se percebe, enfim, que a crítica ao irracionalismo desenfreado que assola o teatro brasileiro no final dos anos 1960 retomará argumentos agora expostos. Em Brecht, esse irracionalismo (expressionismo bruto) é coberto “com a língua metálica da épica” (ROSENFELD 1956: s/p)., formando uma composição esquisita, "brasa envolvida em gelo" (id.), impondo o dispositivo da dialética - da contradição organizada - para a compreensão de Brecht. O irracionalismo epidérmico - para usar uma expressão que é título de artigo fundamental - será duramente criticado por sua falta de dialética que o faz, afinal de contas, ser facilmente absorvido pela cultura burguesa: mas isso fica para depois.

Mais tarde, em 1958, Rosenfeld assiste aos ensaios e participa da montagem de Setsuan com um artigo publicado no programa da peça. Segundo Brandão, seu envolvimento é

[...] indício da voltagem intelectual do projeto. O estudioso analisou a peça e os procedimentos usados por Brecht, enfocando o caráter dialético das personagens inseridas num contexto social. No final de seu texto, Anatol Rosenfeld afirmou que a encenação do TMDC seguia "de perto os processos propostos pelo autor e concretizados no Ensemble de Berlim"; assim, devia ser considerado uma "autêntica versão brechtiana" [...] (BRANDÃO 2009: 320)

Não custa lembrar que, ao analisar a mesma montagem, o maior nome de nossa crítica teatral, Décio de Almeida Prado, faz avaliação demolidora de um suposto esquematismo e reducionismo na obra de Brecht, questionando nela, principalmente, a relação entre política e estética. Em suma, quase todas as avaliações - críticas e teóricas - elaboradas por Rosenfeld recebem sinal negativo por Prado, sobretudo a articulação 'promíscua' 
Flory, A. - A recepção de B. Brecht

entre consciência social e estética (cf. CosTA 1998: 78-80). Não fosse o interesse dos integrantes dos grupos teatrais como o Arena e de poucos críticos como Rosenfeld, sua recepção seria muito diferente em nossas terras. Mas, por questões que vão além do campo unicamente estético - a efervescência política, econômica, cultural, social do Brasil de então - criou-se um cenário promissor para uma recepção ativa de Brecht. No contexto do teatro de Arena, por exemplo, a influência de Brecht em obras decisivas como Revolução na América do Sul, de Augusto Boal (1960) e em A mais-valia vai acabar, seu Edgar, de Vianinha (escrito em 1960 - embora sua produção já se dê fora dos limites do Arena) é lugar-comum da crítica (cf. PRADO 2008: 70; CosTA 2012: 121).

Mas cumpre localizar o modo como se dá essa recepção e sua avaliação. Em 1962, Rosenfeld já identifica e questiona os pontos sobre os quais diverge de parte da crítica brasileira a respeito das obras de Brecht, então já muito discutidas por aqui:

O que Brecht exige é a transformação produtiva das formas, baseada no desenvolvimento do conteúdo social. [...] Isso explica a pesquisa incansável de Brecht no terreno da palavra, do estilo, do verso, do ritmo, da cena, do desempenho do ator, da estrutura de sua arte. Essa pesquisa e experimentação incessantes não deixaram de lhe render censuras e a acusação de ser formalista e esteta, quando na realidade a consciência social e a consciência estética se afiguram inseparáveis. (ROSENFELD apud CAMPOS 1995: 83)

O trecho é curto, porém eloquente. Em Brecht, as novas formas não se ligam unicamente ao campo estético, num plano sistemático autofundante, mas se relacionam ao mundo social. É essa mediação que o leva da palavra (desconfiando dela, como vimos), ou seja, do texto, à cena, ao ator, todos os níveis cooperando para a estrutura teatral. Outra batalha já se apresenta aqui, a de uma dialética entre o texto e a cena que é inerente ao teatro ${ }^{6}$. Não estão certos os que defendem a primazia do texto, nem os que o desprezam em função da cena. Daí sua crítica passar do texto ao trabalho do ator sem que isso se torne um problema. Essa concepção de teatro, aliás, aparece no seu método crítico, que toma diversas formas: da história do teatro alemão à discussão teórica mais cerrada - mas nunca a-histórica - chegando aos ensaios mais livres e à crítica de

\footnotetext{
${ }^{6}$ Brecht não pode ser reduzido ao autor teatral sem tino para a cena: a dialética entre texto e cena para o teatro é um dos pontos centrais do pensamento de Rosenfeld, já aparecendo aqui e desenvolvido em profundidade em artigos decisivos como 'O fenômeno teatral', publicado no livro Texto / Contexto (1996b), discussão que, no entanto, não cabe no recorte desse artigo.
} 
Flory, A. - A recepção de B. Brecht

espetáculos específicos e sua relação com a atualidade mais imediata, como veremos. De acordo com a necessidade do momento, inclusive, sua escrita pende mais para um ou outro gênero, com a clareza de quem sabia discernir o que valia a pena (SCHWARZ apud CARVAlHo 2011). No excerto, aceitando o desafio intelectual, chama às falas os que tentam acusar Brecht de formalismo e de esteticismo por sua procura por novas formas, como se as técnicas de distanciamento valessem por si só, como dispositivos unicamente estéticos. Como já mencionado, essa postura ainda era forte na crítica brasileira de então, contra a qual Rosenfeld se insurge. ${ }^{7}$

A pedido de Prado (1995), Rosenfeld escreve um livro que se tornaria um marco nos estudos teatrais brasileiros, O teatro épico (primeira versão publicada em 1965). Ele se credencia como um dos pontos altos da recepção de Brecht no Brasil porque, em grande medida, vai além de Brecht, ao historicizar o conceito de teatro épico a partir da tragédia grega, detendo-se em momentos específicos desse caminho. Nada mais brechtiano do que acompanhar como, em contextos determinados, foram engendradas formas próprias de expressão do épico, percurso que exige a localização de Brecht no tempo e no espaço para a compreensão de seu pensamento e prática teatrais. A crítica desde seu lançamento o vê como uma referência obrigatória para os estudos de teoria, crítica e prática teatrais, visto o seu amplo alcance e o modo como articula os diversos campos.

O teatro épico é dividido em cinco partes, numa estrutura dialética precisa. $\mathrm{Na}$ primeira se resume a teoria dos gêneros - épico, lírico e dramático -, tomados como formas puras e típicas. Anotando que não há obra pura ou que isso seja critério de avaliação estética, ele traça as principais categorias que marcam os gêneros. Mesmo a abertura para uso adjetivo, num alargamento semântico que leva a expressões como ‘drama lírico' ou 'teatro épico', não questiona a normatividade teórica, mas a reforçam, ao fazê-la mais flexível a adaptável aos materiais literários sem, no entanto, manchar sua falsa universalidade.

\footnotetext{
${ }^{7}$ Vale notar que, em artigo de 1968 a respeito da publicação das obras completas de Brecht em 20 volumes, Rosenfeld retome esse assunto pela perspectiva de Brecht contra Lukács, no contexto do Debate sobre o expressionismo. "Brecht rejeita a doutrina de Lukács porque este associaria o estilo realista a uma forma envelhecida e estéril, quando o que atualmente se impõe ao realista é fazer uso de todos os processos artísticos que facilitem a profunda "penetração na causalidade social". Lançar o realismo contra o expressionismo é uma simplificação, já que o experimento vanguardeiro (que Brecht considera necessário) pode aprofundar e ampliar a apreensão da realidade. A dramaturgia expressionista teria desvendado facetas ignoradas da realidade." (ROSENFELD 1968: 37).
} 
Flory, A. - A recepção de B. Brecht

Da parte II à IV traça um percurso histórico das formas teatrais na dialética com processos sociais, a começar pela tragédia grega, tendo como fio condutor o conceito do épico em teatro. De alguma forma, isso o leva a uma reescrita da história literária a contrapelo, na dicção benjaminiana, pois assume uma perspectiva que a teoria dos gêneros não consegue resolver, visto que a forma dramática pura aceita o épico apenas como ampliação semântica adjetiva. Seu recorte teórico joga luzes na história do teatro sob outro ângulo, antes colocando questões do que as respondendo.

A parte $\mathrm{V}$ mergulha na obra de Brecht, em sua construção teórica e prática, ponto de convergência explícito do livro. Nesse momento, as normas rígidas da dramática pura, e da teoria dos gêneros, estão dialeticamente superadas. Quando lido em confronto com a parte I, a parte V explicita contradições e dissonâncias que não aceitam a harmonização adjetiva. "Na associação da Épica à Dramática - aparentemente uma questão bizantina de classificação e de gêneros - manifesta-se não só o surgir ou ressurgir de novas temáticas, mas uma deslocação decisiva na hierarquia dos valores." (RoSENFELD 1997: 174) Mais adiante, usará o termo ‘transbordamento' para se referir a essa superação dialética. Nas palavras de Carvalho, nesse livro Rosenfeld "revela ao seu jeito a impossibilidade poética da teoria dos gêneros literários", e as categorias dos gêneros literários são convertidas em "conceitos de transição, que permitem o exame dos casos históricos" (CARVALHO 2011).

Como outro ponto de destaque do livro, Rosenfeld realiza um diálogo crítico intenso com a Teoria do drama moderno, de Peter Szondi, livro publicado em 1956 na Alemanha e que viria a se tornar um dos momentos-chave dos estudos teatrais em vários países. Rosenfeld amplia o escopo, indo até os gregos para historicizar e explicar o sentido da apreensão e os modos de expressão do épico ao longo do tempo, o que faz ver como a ruptura do final do século XIX que Szondi intitula 'crise do drama' se insurge contra o 'drama bem-feito' do século XIX, universalizado como forma pura pela teoria dos gêneros. Era importante, no caso brasileiro, que esse percurso mais amplo fosse acompanhável. Além disso, diferentemente da estrutura da obra de Szondi, orienta seu livro para culminar em Brecht. Essa culminação, no entanto, não o coloca no figurino de um gênio; pelo contrário, localiza-o na história, bem como a teoria do teatro épico. Sendo assim, dignifica o trabalho de inúmeros grupos que estavam trabalhando 
Flory, A. - A recepção de B. Brecht

com e a partir de Brecht no Brasil, pois sua teoria exige a passagem pelas obras e pelos contextos em que elas são atualizadas.

\section{$4 \bigcirc$ mito e o herói na série Arena conta (Zumbi, Tiradentes)}

No entanto, o golpe militar de 1964 cria um ponto de inflexão em sua participação na vida teatral brasileira. Cada vez mais ativo e próximo do calor das ruas, Rosenfeld escreve ensaios que dialogavam diretamente com grupos teatrais que, naquele momento, começaram a fazer um teatro de resistência (РЕіXOTO 1987). Essa perspectiva se constitui como um capítulo à parte da recepção da obra de Brecht no Brasil, perspectiva sempre lembrada por Rosenfeld nesses textos. Para o recorte desse artigo, interessa, sobretudo, o ensaio 'Heróis e Coringas', que faz parte da coletânea $O$ mito e o herói no moderno teatro brasileiro (ROSENFELD 1996a) ${ }^{8}$. No entanto, vale a pena começar pelo prefácio escrito pela organizadora do livro, Nanci Fernandes. Ela conta que, tanto em seu trabalho como crítico teatral como em seus cursos de estética, a questão do herói na dramaturgia moderna ganhava destaque. Sendo assim, embora o livro seja uma coletânea que também se atém a essa temática nas dramaturgias de Jorge Andrade, Ariano Suassuna e Dias Gomes, há uma unidade justamente por pensar a questão do herói a partir de nossa configuração histórica e dramatúrgica.

Porém o ensaio relativo ao texto de Boal e Guarnieri e à encenação de Boal da peça Arena conta Tiradentes (embora passe, também, pelo Arena conta Zumbi) deve ser destacado pelo rigor e profundidade com que avalia criticamente texto e encenação (sem deixar de explicar a importância do trabalho, anote-se) e pela amplo espectro de temas que toca e discute, num diálogo muito produtivo com Boal, como esse anota em entrevista; diálogo que o teria motivado a escrever os textos teóricos que publicou junto com o texto da peça. (BOAL Vintém 7: 43) Não é sem motivos que Rosenfeld foi "o mais importante interlocutor do Teatro de Arena nesse momento.” (BETTI 2013: 200).

Algumas poucas palavras sobre o sistema Coringa são importantes para encaminhar a discussão. Em Tiradentes, onde o sistema está maduro, temos a

\footnotetext{
${ }^{8}$ Há uma tese de doutorado inédita, defendida em 2007 na USP por Érica Gonçalves de CASTRO, intitulada Clássicos e cabotinos: a obra crítica de Anatol Rosenfeld, que trata numa de suas seções da crítica do irracionalismo no teatro feita por Rosenfeld e da crítica de Rosenfeld à peça Arena conta Tiradentes, de Boal, embora em uma linha muito diversa da proposta aqui desenvolvida.
} 
Flory, A. - A recepção de B. Brecht

perspectiva épica na narração - (1) coletiva e (2) situada historicamente - (3) de uma versão não oficial da derrota da Inconfidência Mineira, vista a partir de uma posição determinada e afirmada, a do Arena (4). Um Coringa, paulista de 1967 (portanto contemporâneo dos espectadores, em todos os sentidos) assume diversos papéis ao longo da peça que, o tempo todo, perspectiva a narração e a remete, alegoricamente, para o tempo presente, para a ditadura e para o papel das esquerdas que não se deram conta nem conseguiram lutar contra o golpe, nem o faziam então. O Coringa narra, comenta, explica, questiona, como um narrador, em diálogo aberto com o público. Os atores seguiam, portanto, a cartilha brechtiana de distanciamento dos personagens, mostrando-os mais do que os incorporando, conferindo uma atitude crítica também aos personagens que envergavam. Tiradentes, porém, ocupando função protagônica, atuava em estilo naturalista e vivia imerso em seu mundo, assim como o ator que o representava deveria apresentar total empatia com o personagem, construído como herói mítico. Não acompanhava o que os demais viam, não se relacionava com a instância épica operada pelo Coringa, tencionando criar empatia com o público. Enquanto os outros atores trocavam de personagens e o Coringa ocupava o lugar de qualquer um, Tiradentes restava limitado a um intérprete.

Procurava-se, como disse Boal, o particular típico, sintetizando as duas fases anteriores do Arena. A primeira, realista, do autor nacional, estava "ocupada com detalhes e singularidades da vida brasileira e exposta ao perigo de, devido à mera reprodução da realidade empírica, particular, deixar de analisá-la e interpretá-la em profundidade", sendo a segunda a fase de nacionalização dos clássicos, "dedicada, ao contrário, a ideias universais, a "tipos" vagamente postos em referência com a vida brasileira, daí decorrendo outro perigo, oposto, o de o universal ficar "flutuando" por sobre o Brasil" (RosENFELD 1996a: 14). Essas são citações da apresentação da teoria de Boal por Rosenfeld, que nos interessa porque seu método crítico envolve, num primeiro momento, uma apresentação clara e completa da teoria de Boal antes de entregar-se à sua crítica. E mesmo que a síntese em direção ao 'particular típico' não tenha ocorrido em Zumbi e nem em Tiradentes de modo completo, Boal acreditaria que

[...] o 'universal', o mito de Zumbi, com sua estrutura de fábula, não deixou de se associar ao particular, manifesto através de dados jornalísticos, discursos etc, mercê dos quais se aproveitaram fatos recentes da vida nacional, de modo a se tecerem analogias entre a fábula mítica e o momento histórico atual. (ROSENFELD 1996a: 14). 
Flory, A. - A recepção de B. Brecht

Não há sombra de dúvida de que o teatro de Arena levava adiante as pesquisas no campo do teatro épico e político no Brasil, dadas as circunstâncias do momento, e que, nesse sentido, inseria-se no âmbito da recepção de Brecht. A partir de Brecht, do Arena e do contexto brasileiro, Rosenfeld entra na discussão pela porta teórica que leva a outros lugares, especialmente à crítica e ao efeito sobre o público, item que ganha cada vez mais espaço em suas críticas a partir de então. Tratava-se de se aproximar, cada vez mais, das questões materiais sem descurar do nível teórico, sem o qual o pragmatismo perde consistência crítica.

Para Rosenfeld, "é com o sistema do Coringa que a teoria de Boal se afasta parcialmente da de Brecht. Este provavelmente não teria concordado com a separação e junção um tanto mecânica de nível típico e particular, oposição não muito congruente." (ROSENFELD 1996a: 15).

A título de contraposição, vale notar que, em seu livro sobre o Teatro de Arena, Magaldi chama o capítulo relativo à série Arena conta (Zumbi, Tiradentes, etc) de 'Brecht assimilado'. Na análise do Tiradentes, não vê questões relevantes na aplicação de Brecht na cena de Boal, listando a aplicação da música e da função protagônica como tipicamente brechtianos. A análise de Magaldi recai de modo mais incisivo sobre as correspondências entre os anos de 1791 e de 1967, mas não vê incongruências ou falta de dialética na fórmula do 'particular típico' aqui encenada, como se vê na seguinte passagem: "A síntese de estilos se completa com a síntese dos dois métodos fundamentais do teatro moderno - Stanislávski e Brecht unidos com o propósito de se vivenciar uma experiência e ao mesmo tempo comentá-la para o espectador." (MAGALDI 1984: 78). Brecht estaria, portanto, assimilado.

Onde Magaldi encontra síntese, Rosenfeld vê justaposição problemática, e passa a discutir o sistema de modo insuperável e necessário, em tempos em que tantos 'heróis' aparecem diariamente na televisão. Como vimos, não haveria problema, para Rosenfeld, numa articulação em que a contradição levasse a algum sentido dialético, como na expressão ‘brasa envolvida em gelo’, de 1956.

Como Tiradentes é o único personagem que não é cambiável entre os atores, Rosenfeld busca uma necessidade estética para essa desvinculação, e compara o procedimento com A decisão, de Brecht, onde esse processo se justifica, pois nessa peça 
Flory, A. - A recepção de B. Brecht

os revolucionários são anônimos e intercambiáveis. O mesmo não se daria com Gonzaga, Silvério ou Alvarenga, pois a crítica aos personagens já viria do caráter caricato dado a eles. Essa troca, inclusive, poderia causar confusão para o público e desviar a atenção do que seria mais decisivo. Apesar disso, avalia positivamente a técnica dos atores para mostrar ao público que vestiam outro personagem, o que criava um novo repertório para a plateia. Também valoriza a diferença de atuação entre dois atores que interpretam Gonzaga, um mais caricato e outro intelectualizado, à altura do personagem histórico.

Esse parágrafo identifica alguns procedimentos básicos da apreciação crítica ora empreendida por Rosenfeld. Quando possível, vê um determinado procedimento e o avalia à luz da teoria teatral mais condizente, em geral a brechtiana, para apontar tanto erros como acertos. Ao fazê-lo, mostra, também em Brecht, como a desvinculação de ator e personagem não é uma técnica fria, a ser aplicada indistintamente, mas que precisa de uma motivação em cada caso específico. O pensamento vai e vem nesse jogo entre a teoria, o texto dramático e a cena contextualizada. A dinâmica do personagem Gonzaga é discutida com fundo histórico, e o efeito sobre o público é levado em conta, tanto para a apreciação estética quanto para a formação de um repertório. No mesmo diapasão, Rosenfeld avalia que a criação de ilusão plena de realidade necessária ao estilo naturalista de Tiradentes não se efetiva num palco em forma de Arena, especialmente pequeno como esse em questão. $\mathrm{O}$ estilo naturalista pediria um palco italiano, grande e separando completamente palco e plateia, como num long shot do cinema.

A situação fica ainda agravada e mais complexa porque esse personagem de estilo naturalista deve ser construído como herói mítico. Relembrando, o particular típico viria da articulação do universal do mito (Tiradentes) justaposto à particularização do localizado historicamente (Coringa e demais personagens).

Mas precisamente o nível universal (mítico) deve ser representado pelo estilo naturalista, isto é, um estilo que visa ao detalhe, à minúcia, ao passo que o nível singular/particular da atualidade pertence ao Coringa, cuja função é precisamente "a abstração mais conceitual." (ROSENFELD, 1996a: 33).

Nada indica que essa contradição tenha sido proposta para fins "dialéticos". (ROSENFELD, 1996a: 22). 
Flory, A. - A recepção de B. Brecht

Assim, o mito, que é universal e antipsicológico, é apresentado a nós por um estilo psicologizante, o naturalismo; ao passo que o traço épico do Coringa, coletivizante e, nesse sentido, distante da psicologia individual, é responsável por nos aproximar dos detalhes do dia a dia, das particularidades. Antes de dialético, haveria uma contraposição que levaria o sistema a um beco sem saída.

Novamente, aqui nos deparamos com uma reviravolta típica do pensamento dialético de Rosenfeld, pois dessa situação aparentemente bloqueada ele se sai com o recurso à cena viva. Na prática do palco, à revelia da teoria de Boal, o estilo naturalista não funciona, apesar dos esforços do ator David José. Isso se dá, como já visto, pela disposição e tamanho do teatro de Arena, pela justaposição com o outro registro cênico, e também pelo fato de o Coringa assumir o lugar do protagonista em cenas nas quais esse não pudesse atuar de modo naturalista, como por exemplo quando monta um cavalo. Quando Tiradentes é enforcado, também apenas se alude ao enforcamento, não havendo esforço realista mais significativo, com o quê, afinal de contas, na encenação, a pureza do estilo naturalista e a grandeza do herói mítico fiquem manchadas pelas tintas épicas da distância. Com algum toque de ironia, Rosenfeld ainda diz que o mesmo - a cena funcionar apesar e contra a teoria - também ocorre, por vezes, com Brecht.

Esse 'salvamento' de Boal ocorre mais adiante, numa das mais belas páginas do ensaio. Segundo Rosenfeld, Boal não teria uma concepção clara e amadurecida do conceito de herói, e se aproximaria dele com alguma reserva. Esse seria o motivo pelo qual faz uma longa argumentação para defendê-lo nos textos teóricos sobre o Coringa, forçando a mão nos exemplos brechtianos. Talvez por isso mesmo, como uma expressão desse desassossego, Boal teria ‘naturalizado' o herói mítico. Nas palavras de Rosenfeld: "É por isso mesmo que o cerca de todo um aparelho crítico distanciador para que não escape. E talvez seja por isso que procura apresentá-lo de forma naturalista: para que o mito não seja muito mítico.” (RosENFELD 1996a:24). Novamente, Boal é jogado contra Boal, e Rosenfeld não se faz de rogado em anotar um acerto crítico talvez inconsciente, operando por trás das palavras do próprio Boal. Sendo assim, dialeticamente, seria um acerto o erro acima discutido, pois no fundo não se queria um "mito muito mítico".

Outro ponto importante do ensaio versa sobre a concepção do herói, discutindo sua exequibilidade no cenário burguês, onde tudo é mediado socialmente e não se pode 
Flory, A. - A recepção de B. Brecht

mais agir sozinho, contando unicamente com a própria força de vontade e senso de justiça, pois essa depende de um sistema legal que não remonta ao indivíduo, mas à sociedade, nem sua ação depende apenas de si mesmo. Se o herói tem essa caracterização individualista, seria realmente necessário num mundo como o de hoje, e especialmente por um teatro político e, afinal de contas, épico? O herói não teria uma dimensão facilmente manipulável pela ideologia burguesa que deveria ser combatida? Brecht diz que feliz é um povo que não precisa de heróis, ao que Boal responde: "Nós não somos um povo feliz. Por isso precisamos de heróis." (BOAL apud ROSENFELD 1996a: 28). Rosenfeld admite o comportamento heroico, mas questiona a existência do herói num tempo distinto da 'época de heróis' de Hegel (Heroenzeit), no qual a realidade plena recai sobre o indivíduo, que nem mesmo pode ter consciência disso, pois ela já o afastaria do mundo mítico.

Em suma, esses são alguns dos aspectos da leitura que Rosenfeld faz do Sistema Coringa e da encenação de Arena conta Tiradentes. Rosenfeld está longe de fazer uma crítica demolidora do trabalho de Boal, pelo contrário. Como diz,

[...] apesar de todas as dúvidas, é preciso destacar que dificilmente se encontrarão no teatro brasileiro dos últimos anos experimentos e resultados dramatúrgicos e cênicos tão importantes como Zumbi e Tiradentes, como proposição renovadora do teatro engajado. A poética de Boal é um ensaio ímpar e completamente singular no domínio do pensamento estético brasileiro. As objeções levantadas, mais que negar, pretendem discutir as teses de Boal. [...] Talvez seja necessário repensar mais uma vez certas teses fundamentais para que o teatro de Arena alcance eficácia ainda maior na análise e interpretação crítica da realidade e na sua comunicação vigorosa, teatral, ativante e divertida, ao público específico a que se dirige, no âmbito das condições concretas da sala de que dispõe, em face do momento histórico em que se insere a sua obra. (ROSENFELD 1996a: 38; negritos meus)

Essa avaliação absolutamente positiva que Rosenfeld faz passa pelos vários níveis de análise que sua crítica põe em circulação, e que estão em parte determinados pelo contexto brasileiro de então, o que fizemos questão de ressaltar em negrito: crítica da realidade e sua mediação pela expressão artística, o caráter formador do teatro, visando um público específico em contexto idem, sem deixar de lado que o espaço do Arena, como todo espaço cênico e dramático, já é um enunciado por si só que precisa ser levado em conta. Como veremos a seguir, nos textos referentes ao irracionalismo no teatro sua avaliação será, no mais das vezes, ácida e mordaz contra um teatro que se 
Flory, A. - A recepção de B. Brecht

quer renovador, moderno e até revolucionário, mas que, a despeito das aparências, pode resultar num teatro palatável e desejado pelo status quo burguês.

\section{Rosenfeld contra as tendências irracionalistas no teatro brasileiro}

Os artigos de Rosenfeld sobre o irracionalismo no teatro marcam uma mudança de tom e de voltagem em sua obra. Cada vez mais, a forma de seus textos ganha em virulência, ironizando, quando não parodiando, a teoria e a cena daí decorrentes. Os textos principais são 'O teatro agressivo', da coletânea Texto/Contexto, de cunho mais teorizante, e várias críticas reunidas no volume Prismas do teatro (entre eles, o já citado "Irracionalismo epidêmico"; "O teatro brasileiro atual"; "Living Theatre e o grupo Lobo"; "O balcão, de Garcia"; "Mais respeito ao texto"), além do artigo de jornal "Na selva das cidades". No mais das vezes, mesmo quando trata de grupos estrangeiros no Brasil, um dos focos centrais desses artigos é a estética de José Celso, especialmente por seus manifestos (muitas vezes desenvolvidos em entrevistas) e as encenações de $O$ rei da vela, Galileu Galilei e Na selva das cidades. O nome de Brecht se impõe pelo simples fato das duas últimas peças serem de sua autoria, mas seu nome já vem à tona em textos anteriores a essas encenações.

Embora o artigo "O teatro brasileiro atual" tenha sido publicado originalmente em 1969, nesse artigo ele comenta, de modo muito positivo, a encenação de $O$ rei da vela por José Celso em 1967. Anota o tratamento de choque inspirado em Artaud e assumido pelo diretor, mas mantém certa distância da avaliação crítica mais detida. $\mathrm{O}$ próprio caráter de passar em revista os acontecimentos teatrais dos últimos anos contribui para a apresentação mais ou menos inócua dos recursos do texto e daqueles utilizados pelo diretor.

Essa perspectiva muda muito no ensaio 'O teatro agressivo'. Nele, agora mirando diretamente esse objeto, Rosenfeld retoma, a seu modo, o método crítico já visto em outros ensaios. O método crítico de Rosenfeld anota o recado e o historiciza, compreendendo o trabalho de Zé Celso como ligado às rupturas expressionistas, surrealistas, dadaístas, entre outras, e ligado à urgência de se posicionar num mundo cada vez mais convulsionado a que a arte deve dar expressão. Romper com a concepção 
Flory, A. - A recepção de B. Brecht

que coloca a arte e a sociedade como campos inacessíveis um ao outro seria questionável, e a agressão serve bem a isso, apresentando esses desdobramentos de modo compreensivo. De fato, como elemento entre outros na estrutura da obra, Rosenfeld concorda com a necessidade e produtividade do teatro agressivo, mas não quando se torna dominante, irracional em todos os seus momentos. Depois disso, centra seu texto em aspectos cruciais do teatro de Artaud.

Se há pouco a articulação se deu entre Stanislávski e Brecht (em Boal), agora o diálogo se dá entre Artaud e Brecht, mas com o cuidado de anotar a diferença entre o teatro naturalista do russo, que é uma das balizas da obra de Brecht, e o francês, pois Artaud apresenta sérias dificuldades para uma mediação dialética. É fato que o caráter épico que marca o texto de Oswald de Andrade nos remete a uma relação produtiva com Brecht. Rosenfeld, porém, encontra antes Artaud que Brecht na montagem de $O$ rei $d a$ vela, o que é corroborado pelo manifesto de Zé Celso centrando fogo contra o teatro racionalista, fazendo a apologia de uma arte agressiva, provocativa, que desferisse "porradas" na classe média que vai ao teatro.

Mas é preciso, antes de chegar à crítica pela remissão quase única de Artaud, nas possibilidades de aproximação que existiriam entre dois dos mais influentes homens de teatro no século XX. Não custa lembrar que, na mesma época, enquanto Magaldi não viu questão teórica mais relevante na justaposição de Brecht e Stanislávski, muitos críticos verão nas obras de Zé Celso também uma síntese feliz e acurada de Brecht e Artaud, como SiLVA (2008) e MostaÇO (1982). De certa forma, Rosenfeld se contrapõe a essas leituras, sendo uma das vozes mais lúcidas e atuais nesse debate.

Para Rosenfeld, não seria possível aproximar de Brecht as posições de Artaud ao conceber o teatro como um espaço ritual e, mais ainda, como lugar para a busca da libertação do inconsciente. Se os dois questionam a distância estética apaziguadora entre o palco e a plateia, que pede consumidores passivos, isso se dá de maneira completamente diferente em cada um. Artaud pretende romper a separação entre palco e plateia para fazer disso uma coisa única, ao passo que Brecht, para romper com a ilusão, preferia um palco italiano para desmontar, pelo processo de encenação e por novas relações com o público, os discursos estabelecidos por essa organização espacial. Mais do que isso: 
Flory, A. - A recepção de B. Brecht

O que, no entanto, os separa radicalmente é o racionalismo crítico do primeiro e o irracionalismo "incandescente" do segundo; a severa disciplina estética e intelectual daquele (pelo menos na sua fase madura) e o impulso anárquico deste. Brecht criou um teatro sociopolítico, de tendência imanentista, Artaud imagina um teatro essencialmente metafísico. [...] A participação a que Brecht visa é crítica, ao passo que Artaud, desejando criar uma nova ilusão, pensava numa participação mágico-ritual. (ROSENFELD 1996b: 49)

Sendo assim, seria muito difícil conseguir uma mediação dialética entre os dois, visto que não apenas seu palco e seus textos diferem radicalmente, mas também a concepção de teatro e a relação com o público. Essas questões serão retomadas mais à frente, quando discutirmos a encenação de Galileu Galilei. Após isso, e sem desferir sua crítica diretamente à encenação de Zé Celso - ironicamente, mais tarde Rosenfeld dirá que sua invectiva contra o teatro agressivo não mira nenhuma obra existente no teatro brasileiro, mas talvez em gestação - expõe em que condições e os motivos pelos quais o teatro agressivo se torna inócuo e esterilizado, apesar da violência modernosa, quando ocorre a elevação da violência a

[...] princípio supremo, em vez de apenas elemento num contexto estético válido, [caso em que] afigura-se contraditório e irracional. [...] Contraditório ainda porque a violência em si, tornada em princípio básico, acaba sendo mais um clichê confortável que cria hábitos e cuja força agressiva se esgota rapidamente. (ROSENFELD 1996b: 56).

Em suma, a "ira recalcada" atirada contra o público dificilmente criaria um espaço de reflexão que pudesse mudar a posição dos espectadores, antes voltados a se comprazer com os ataques - quando se associam aos agressores - ou desviando-se das palavras e objetos arremessados ao público. Afinal de contas, em tempos de indústria cultural, rapidamente essas propostas são amplamente difundidas, de modo que o público burguês contra o qual a peça se volta já sabe de antemão o que receberá, e se compraz sadomazoquisticamente ou se sente reforçado em seus valores burgueses por sustentar um teatro que lhe cospe na cara. Deste modo, funciona como um produto de consumo fácil, no qual se conta com alguns arranhões como se espera de esportes radicais nos dias de hoje. O caráter ritualístico coopera com esse estado onírico-ritual, envolvente, não afeito ao discurso crítico.

A encenação de Galileu Galilei por Zé Celso é de 1968, com estreia, por sinal, no dia da decretação do AI-5. Vindo de duas experiências renovadoras - O rei da vela e 
Flory, A. - A recepção de B. Brecht

Roda-viva - e sob a influência cada vez maior de Artaud, Zé Celso aceita montar a peça depois de pressionado por Fernando Peixoto e Renato Borghi. O grupo, então, estava dividido entre os representativos (os mais antigos, como os dois mencionados) e a ralé, que fez parte do coro de Roda-viva. Essa vertente dominada pela estética de Artaud, aquela cada vez mais inclinada ao racionalismo do teatro brechtiano. Zé Celso, entre as duas correntes, resolveu o impasse inserindo um caráter irracionalista na montagem. Como visto há pouco, estaria aqui a possibilidade de síntese dialética entre Brecht e Artaud, contra a qual já se posicionara Rosenfeld. MostAÇO (1982: 126-7), no entanto, entende a encenação como "um vigoroso exercício de teatro dialético" e, indo ainda mais longe, afirma que, "sem sombra de dúvida, foi a mais rigorosa montagem brasileira inteiramente assimilada segundo as determinações do teatro épico", ao articular Brecht com a "iconoclastia feérica dos novos tempos."

Isso, porém, será contraposto por um dos mais importantes participantes do grupo, Fernando Peixoto. Para ele, embora partes do espetáculo fossem marcadas por certa lógica, sensatez e equilíbrio,

[...] na cena do carnaval, a mais importante, onde conceitualmente a sabedoria chega ao povo, onde ela explode na feira popular, nesse momento partia-se, no nosso espetáculo, para o irracionalismo solto, para um anárquico desenfreado. E objetivamente negavamse todas as outras cenas... (РЕIXOTO 1987: 235).

De certo modo, Peixoto e Zé Celso concordam com a tentativa de articulação entre uma tradição brechtiana ortodoxa e outra mais livre, mais aberta à experimentação. Nos termos de Iná C. CosTA (2012: 123-4), que ela enfatiza ser uma simplificação, haveria então o grupo dos brechtianos ortodoxos e dos antibrechtianos, não só no Brasil como no mundo; Peixoto estaria no primeiro grupo, e Zé Celso no segundo. Como trabalharam juntos na encenação, a montagem seria histórica por um lado (por, justamente, articular duas posições bem distintas quanto ao pensamento brechtiano, o que normalmente aconteceria em peças diferentes) mas, por outro, faltaria dialética para mediar as duas perspectivas. Como se vê, essa avaliação corrobora a de Peixoto, ao dizer que a cena do carnaval negava, objetivamente, as demais cenas. 
Flory, A. - A recepção de B. Brecht

Rosenfeld está com esses últimos, como aponta em ensaio intitulado "Mais respeito ao texto" ". Neste ensaio, comenta um texto de Pedro Dantas exigindo dos diretores maior respeito aos textos teatrais. Rosenfeld coloca-se veementemente contra a argumentação de que a encenação estaria subordinada ao texto, esse primário e primeiro em relação àquela. Não obstante a dura recriminação que dirige a Dantas, matiza seu verbo com as seguintes palavras:

\begin{abstract}
Não se pode deixar de dar razão ao Sr. Pedro Dantas, quando se pensa, por exemplo, em certa encenação de Galileu em que ao público, quase à força, era imposta a tarefa de subir ao palco para formar uma "corrente de fluidos e vibrações" e participar de rituais idiotas que não tinham nenhuma relação com a peça de Brecht e muito menos com as descobertas do genial físico. (ROSENFELD 1993: 238).
\end{abstract}

Não há dúvida de que Rosenfeld se refere à montagem de Zé Celso, e sua crítica consegue articular mais do que parece à primeira vista. Pois não está em jogo defender uma posição pró-texto e comentar a dura lida que esse sofre quando sobe ao palco, por conta tanto da efemeridade constitutiva da cena viva quanto das determinações de um diretor e de atores que conspurcariam a pureza do texto. O artigo em específico e a obra em geral de Rosenfeld não deixam dúvida sobre isso. O problema estaria numa adaptação que não estivesse à altura de atualizar a dialética de Brecht naquele momento das artes e da vida no Brasil, em favor de uma voga irracionalista que assume concepções opostas ao pensamento de Brecht em relação a quase todos os aspectos relevantes de sua obra, alguns já mencionados ao longo desse artigo.

Após essa encenação, em 1969 Zé Celso dirige Na selva das cidades, uma peça do período 'expressionista' de Brecht que, portanto, estaria imune ao racionalismo tacanho que o diretor creditava ao dramaturgo alemão maduro. Sua montagem histórica, exuberante e forte, transbordava o ímpeto irracionalista típico de certo expressionismo.

No artigo para jornal $\mathrm{Na}$ selva das cidades, no entanto, Rosenfeld começa, justamente, por questionar essa entrega à verve irracionalista operada por Zé Celso ao revisitar um texto supostamente expressionista, sem deixar transparecer as ressalvas que o próprio Brecht fez a respeito da obra, historicizando-a. Para isso, Rosenfeld lembra que o texto de Brecht tem duas versões, e se é verdade que na primeira o jogo

\footnotetext{
${ }^{9}$ As aspas fazem parte do título do ensaio, e significam que se trata de uma citação, com a qual Rosenfeld concorda apenas em parte, argumento que desenvolve no mesmo.
} 
Flory, A. - A recepção de B. Brecht

expressionista fica evidente (pois os personagens principais, Garga e Schlink, são expressões de uma única subjetividade), na segunda versão Brecht se afasta dessa perspectiva e reforça o que já estaria mesmo latente no texto primeiro, com a mudança psicológica e comportamental da personagem Garga. Aos poucos, esta personagem abandona o idealismo romântico de recusar o dinheiro de Schlink, que quer comprar a sua capacidade de julgamento. Com isso, Garga (e Brecht) se afasta da concepção expressionista inicial. Não vai mais ao Taiti, mas a Nova Iorque, aceita friamente o dinheiro que no início da peça recusara, e põe fim a qualquer idealização.

Após essas ressalvas quanto ao texto usado por Zé Celso, Rosenfeld discorre sobre a encenação. Primeiro, valoriza o irracionalismo da mesma por estar adequado ao texto, em alguma medida.

Entretanto, a linha do pensamento de Brecht, já então assaz racional, naufraga até certo ponto nessa fúria avassaladora, nesse pandemônio dionisíaco de imagens e ruídos, nesse conjunto audiovisual de fascínio infernal. Perde-se, em parte, o constante atrito entre essa linguagem fria e a matéria incandescente. José Celso insiste em conservar o jovem Garga até o fim tão puro, tão rimbaudiano e tão absoluto como surge no começo. [...] Nesse ponto a liberdade do diretor, em face do texto, certamente ultrapassou os limites. Aplicado à Selva, omite aspectos de um Brecht já mais ambíguo, mais "dialético", que está em vias de afastar-se do expressionismo. (ROSENFELD 1969: s/p.)

A crítica de Rosenfeld, como se vê, retoma aspectos de seu artigo "Disciplina do coração", de 1956, em que já mostra como a entrega completa ao expressionismo, sem o matiz da dialética materialista, seria incorreto em Brecht. Com mais razão ainda para o momento pelo qual passava o país. A leitura de Zé Celso, nesse sentido, não faria jus nem à Brecht nem ao momento histórico brasileiro.

Devemos perceber que sua crítica mira a expressão não-contraditória do texto expressionista, como se a arte pudesse se bastar a si mesma, fechar-se sobre si e universalizar-se, tornar-se absoluta. Deixaria, então, para o recuo subjetivo o único caminho emancipatório, em termos de salvação metafísica, quando o tempo histórico exigia posição ativa. Seria possível trazer para esse comentário de Rosenfeld as considerações que ele mesmo tece a respeito da encenação de $O$ balcão, de Genet, por Victor Garcia. Depois de enaltecer as mudanças que o diretor inscreveu no espaço cênico e dramático, fazendo o Balcão numa espiral ascensional que provocava 
Flory, A. - A recepção de B. Brecht

vertigens, e defender que essa leitura fazia jus ao texto, resultando numa encenação extraordinária, ele termina assim, de modo incisivo:

Entretanto, o teatro é uma instituição que faz parte do todo do contexto cultural. A partir dessa visão mais ampla, a encenação de Garcia produz certo desconforto em quem julga extremamente dúbias - mas nem por isso menos dignas de manifestação - as tendências irracionalistas que atualmente se alastram pelo mundo, também no campo cênico. Antonin Artaud merece ser respeitado como um dos grandes teóricos do teatro moderno [...] Mas seu anarquismo foi refutado pela história, sua teosofia gnóstica e sua denúncia da razão, se unilaterais, só podem prejudicar o teatro. O teatro é também e sobretudo um lugar de lucidez, de crítica racional, de discussão intelectual de valores - fato que, evidentemente, não nega, antes exige, a intensa participação emocional. É digno de nota que [...] Peter Brook, que tanto deve a Artaud, ultimamente (no seu livro The Empty Space) lhe critica a exaltação das "forças inconscientes", indagando se não haveria um "odor fascista no culto do irracional." (ROSENFELD 1993: 178).

\section{Considerações finais}

As perspectivas críticas de Anatol Rosenfeld que seguimos de perto nesse artigo estão, de certo modo, atualizadas no cenário brasileiro atual. A tendência irracionalista encontra eco na performance verbal e teatral do grupo Pocha Nostra, incluída nas atividades oficiais do XIV Simpósio Internacional Brecht em 2013, a ponto de criar a impressão de que algumas das críticas de Rosenfeld se dirigiam ao grupo. Por outro lado, as perspectivas no campo dialético também ganharam espaço a partir dos anos 1990.

Uma lista considerável de pesquisadores e de homens de teatro retomam os trabalhos de Rosenfeld, aí incluídos nomes como os de Roberto Schwarz, José Antonio Pasta, Iná Camargo Costa e Sérgio de Carvalho, entre outros. Como regra geral, não deixam de lado a necessidade de buscar na forma teatral uma mediação com os processos históricos mundiais do capitalismo e, também, suas feições brasileiras. Contra o vale-tudo que canoniza Brecht e o encontra em qualquer manifestação artística contemporânea, e contra sua incorporação por quaisquer tendências irracionalistas, a recepção de Brecht no Brasil também está à altura da pesquisa estética no terreno anticapitalista. Pensamos que a revisitação da obra de Rosenfeld pode ser um caminho para uma crítica contundente e necessária em tempos como os de agora, em que a falta de alternativas para sequer dar nome adequado às diversas crises (ambientais, políticas, 
Flory, A. - A recepção de B. Brecht

econômicas, sociais, culturais) que vivemos, e seus pressupostos aparentemente universais, dificulta até mesmo a formulação de um pensamento crítico.

\section{Referências bibliográficas}

BENJAMIN, Walter. O teatro épico. In: Idem. Obras escolhidas vol. I: magia e técnica, arte e política. São Paulo: Brasiliense, 1996.

. Bert Brecht. In: Idem. Documentos de cultura / documentos de barbárie. São Paulo: Cultrix / Edusp, 1986: 121-25.

BetTI, Maria Sílvia. O teatro de resistência. In: FARIA, João R. (dir.) História do teatro brasileiro vol. 2: Do modernismo às tendências contemporâneas. São Paulo: Perspectiva / Edições Sesc, 2013: 194-215.

BOAL, Augusto. Nunca termina quando acaba. Entrevista. In: Revista Vintém $n^{o}$ 7. São Paulo, 2009: 40-3.

BRANDÃo, Tânia. Uma empresa e seus segredos: Companhia Maria Della Costa. São Paulo: Perspectiva; Rio de Janeiro: Petrobrás, 2009.

CAmpos, Cláudia de Arruda. Zumbi, Tiradentes. São Paulo: Perspectiva, 2004.

CAMPos, Haroldo de. Uma convergência textual. In: Sobre Anatol Rosenfeld. GUINSBURG, J.; MARTINS FILHO, P. (orgs). São Paulo: Perspectiva, 1995: 81-92.

CARvalHo, Sérgio de. Questões sobre a atualidade de Brecht. In: Introdução ao teatro dialético: experimentos da Companhia do Latão. São Paulo: Editora Expressão Popular, 2009: 39-54.

A liberdade intelectual de Anatol Rosenfeld. In: Escritos de trabalho de Sérgio de Carvalho. Publicado em 17 de junho de 2011. Disponível em http://www.sergiodecarvalho.com.br/?p=1058. Acesso em 25 de junho de 2013.

CASTRO, Érica G. Clássicos e cabotinos: a obra crítica de Anatol Rosenfeld. Tese de doutorado inédita defendida na USP em 2007.

CostA, Iná Camargo. A hora do teatro épico no Brasil. Rio de Janeiro: Paz e terra, 1996. . Sinta o drama. Petrópolis: Vozes, 1998.

. Nem uma lágrima: teatro épico em perspectiva dialética. São Paulo: Editora Expressão Popular / Nankin Editorial, 2012.

A produção tardia do teatro moderno no Brasil. In: Revista Discurso - Depto de Filosofia USP n ${ }^{\circ}$ 18: 97-130, 1990.

ELLIS, Lorena B. Brecht's reception in Brazil. New York: Peter Lang, 1995.

Guinsburg, J.; Martins Filho: (orgs) Sobre Anatol Rosenfeld. São Paulo: Com-Arte, 1995.

Lehmann, Hans-Thies. Teatro pós-dramático. Trad. Pedro Süssekind. São Paulo: Cosac Naify, 2007.

MAGAldi, Sábato. Um palco brasileiro: o Arena de São Paulo. São Paulo: Brasiliense, 1984.

Mostaço, Edelcio. Teatro e política: Arena, Oficina e Opinião. São Paulo: Proposta Editorial, 1982.

PASTA, José Antonio. Trabalho de Brecht: breve introdução ao estudo de uma classicidade contemporânea. $2^{a}$ Ed. São Paulo: Duas Cidades: Ed. 34, 2010.

. Brecht: a beleza materialista. In: Folha de S. Paulo. Caderno Mais. Domingo, 8 de fevereiro de 1998. 
Flory, A. - A recepção de B. Brecht

PEIXOTO, Fernando. O teatro de Brecht aqui hoje. In: BADER, Wolfgang. (org) Brecht no Brasil: experiências e influências. Rio de Janeiro: Paz e terra, 1987: 25-37.

. O papel de Brecht no teatro brasileiro: uma avaliação. In: BADER, Wolfgang. (org) Brecht no Brasil: experiências e influências. Rio de Janeiro: Paz e terra, 1987: 232-41.

Pocha Nostra. Manifesto 2012. Endereço eletrônico: http://www.pochanostra.com/ Acesso em 20 de junho de 2013.

PRADO, Décio de A. O teatro brasileiro moderno. São Paulo: Perspectiva, 2008.

. Um clerc perfeito. In: GuInsbuRg, J.; MARTIns Filho: (orgs) Sobre Anatol Rosenfeld. São Paulo: Com-Arte, 1995: 73-79.

Rosenfeld, Anatol. Prismas do teatro. São Paulo: Perspectiva/Edusp/Editora da Unicamp, 1993.

. O teatro épico. São Paulo: Perspectiva/Edusp/Editora da Unicamp, 1997.

. Brecht e o teatro épico. São Paulo: Perspectiva, 2012.

. O mito e o herói no moderno teatro brasileiro. São Paulo: Perspectiva/Edusp/Editora da Unicamp, 1996a.

. O teatro agressivo. In: Texto/Contexto I. São Paulo: Perspectiva/Edusp/Editora da Unicamp, 1996b: 45-58.

. On the road. São Paulo: Perspectiva, 2006.

. Na selva das cidades. In: O Estado de São Paulo. Dia 8 / nov / 1969.

. A disciplina do coração. In: O Estado de São Paulo. Dia 27 / out / 1956.

. Brecht contra Lukacs. In: O Estado de São Paulo. Dia 3 / fev / 1968.

SARTINGEN, Kathrin. Brecht no teatro brasileiro. Trad. José Pedro Antunes. São Paulo: Hucitec, 1998.

SCHWARZ, Roberto. Altos e baixos da atualidade de Brecht. In: Sequências brasileiras. São Paulo: Companhia das Letras, 1999: 113-150.

SILVA, Armando S. Oficina: do teatro ao te-ato. São Paulo: Perspectiva, 2008.

Szondi, Peter. Teoria do drama moderno [1880-1950]. Trad. Luiz Sérgio Repa. São Paulo: CosacNaify, 2001.

Recebido em 01/08/2013

aceito em 29/09/2013 